\title{
Preliminary Study on the Mechanism for Adaptation of Stipagrosits Pennata to Desert
}

\author{
Baohua Gong, Jianbo Zhu \& Hongying Zhao \\ National Key Laboratory of Agricultural Biotechnology, College of Life Science \\ Shihezi University, Shihezi, Xinjiang 832003, China \\ E-mail: javaxsun@163.com \\ Yuxing Zhang (Corresponding author) \\ National Key Lab of Tropical Biotechnology Institute \\ Chinese Academy of Tropical Agricultural Sciences, Haikou, Hainan 571101, China \\ E-mail: zyx2027193@163.com
}

The research is funded by Doctoral Foundation of the XPCC (Xinjiang Production and Construction Corps). No. $2006 j$ c07 (Sponsoring information)

\begin{abstract}
Psammophyte can resist drought through different mechanism, such as small and thin leaves, leaves covered with wax, well developed roots. As typical psammophyte, stipagrosits pennata' root form entwined structure with sand, therefore shows excellent drought tolerance. This paper describes the mechanism of the adaptation of stipagrosits pennata to desert from different aspects such as morphology, anatomical structure and stress simulation.
\end{abstract}

Keywords: Stipagrosits pennata, Drought tolerance, Desert, Entwined root

\section{Introduction}

In severe circumstances, such as drought, salinity, extreme temperature, plants activate all their physiological and metabolic defense systems to respond abiotic stress. Tolerance and susceptibility are complex matters of abiotic stress adaptation. Abiotic stress is the major cause of yield reduction of plant. Annual reduction caused by abiotic stress amounts more than 50\% (Boyer J S, 1982, p. 443-448; Bray E A, 2000, p. 1158-1249). Therefore, study on the adaptation of plant to severe circumstances has positive and practical significance. Among abiotic stresses globally, drought is the main reason causing yield reduction. Plants in drought activate their physiological changes and developmental changes during growth process (Wang W, 2003; Vinocur B, 2005; Chaves M M, 2004; Shinozaki K, 2003; Yamaguchi-Shinozaki K, 2005). Plants in severe circumstances exhibit not only physiological and biochemical changes, but also morphological and structural changes.

Growing in the above-described severe environment, psammophyte forms special morphological structures, such as small and curling leaves, leaves covered with vegetable wax, short stems, entwined roots, all for the adaptation to the desert climate. Stipagrosits pennata, evolved in desert climate for long time, exhibits a form excellent in resisting drought, wind erosion and sand burying.

Stipagrosits pennata genera, including about 150 species, are found widely in extratropical and subtropical drought area. There are total 11 species in China, 3 species in Xinjiang, mainly in the Gurban Tongut Desert in North Xinjiang. With excellent tolerance to drought, wind erosion and sand burying, stipagrosits pennata is a perfect sand-fixing plant. Together with C.leucocladum, C. henopodiaceae and other plants with good sand tolerance and sand adaptation, it forms sand-tolerant plant community (Mamat, Yiti, 1990, p. 51-56). 


\section{Materials and methods}

\subsection{Studied samples}

Stipagrosits pennata and their seeds come from Moguanchu, 148 Corps of Shihezi, Xinjiang, China.

\subsection{Observation on ecology of stipagrosits pennata and effects of temperature on its stomatal conductance}

The effects of temperature on stomatal conductance of stipagrosits pennata are investigated in field by LICOR LI-6400 V4.0.1.

\subsection{Anatomic experiment on the structure of entwined root}

Wash the seeds by tap water for 3 times, then rinse the seeds by distilled water for 3 times. In an aseptic container, disinfect the seeds with $75 \%$ alcohol for $45 \mathrm{~s}$ under a bacteria-free environment, then with $0.1 \%$ mercuric chloride for 8 min (Mao, Weiguang, 2006, p. 116-118). Keep the sterilized seeds in culture medium (1/2MS+2.0 mg/L GA3) for germination, and change to MS+0.3 mg/L NAA after 25 days (Zhou, Jiyuan, 1997, p. 77-82; Chen, Xuesen, 1997, p. 373-377). Seedlings' root will grow bigger and thicker, and also grow out lateral roots. With about 20 days more, seedlings will grow up with their roots extending out from $0.2 \mathrm{~mm}$ to $1 \mathrm{~mm}$. The entwined structure of root is obvious visible. On this occasion, however, this may not happen to every seedling. At this moment, the size of seedling's root is nearly same as the one in wild. With further growth, the root grows longer but thicker.

\subsection{Simulation experiment on the stress adaptation to desert}

Collect 1-year old stipagrosits pennata from Mosuowan Desert of Shihezi of Xinjiang in China and plant them in a plant pot with $5 \mathrm{~kg}$ sand per pot. Simulate the drought stress at different concentration of PEG6000 after two-week domestication in laboratory. Assuming 3 gradients of PEG stress processes: $0,10 \%$ and $30 \%$ with 8 pots per gradient (non-stress gradient is taken as the Control Group). Use the saturated weighing method to maintain their water content. Specifically the procedure is as following: take weigh measurement on each pot at 19:00 every day; refill the lost water to keep the same water content; collect the samples within 72 hours of stress process; choose 3 pots of seedlings with same growth condition as the studied materials; take 3 parallel samples from each pot.

2.4.1 Effects of PEG6000 on membrane permeability

Conductivity process (Hao, Zaibin, 2004).

(1) Rinse the leaves of both the Treatment Group and the Control Group with deionized water, use clean filter paper to absorb water from leaves' surface, cut leaves into segments of $2 \mathrm{~mm}$, and then keep them in clean scaled test tubes.

(2) Introduce $10 \mathrm{~mL}$ deionized water into leaf-contained tubes.

\subsubsection{The effects of PEG on the content of soluble protein}

Coomassie Brilliant Blue method (Hao, Zaibin, 2004) is applied. Weigh $0.5 \mathrm{~g}$ fresh stipagrosits pennata leaves, grind them together with $2 \mathrm{~mL}$ distilled water into paste, centrifuge at $4,000 \mathrm{r} / \mathrm{min}$ for 20 minutes, take $1.0 \mathrm{~mL}$ supernatant and drop it into a tube, add $5 \mathrm{~mL}$ Coomassie brilliant blue solution (G-250) and thoroughly mix them. After 2 minutes, measure the absorbance at $595 \mathrm{~nm}$ by colorimetric method. Find the protein content from the specification curve, calculate the content of soluble protein in sample with the following formula (1).

$$
\mathrm{Cs}=(\mathrm{C} \times \mathrm{VT}) /(\mathrm{V} 1 \times \mathrm{FW} \times 1000)
$$

Here, Cs $(\mathrm{mg} / \mathrm{g})$ represents the content of soluble protein; C $(\mu \mathrm{g})$ represents the content of soluble protein out of the specification curve; VT $(\mathrm{mL})$ represents the total amount of extracted sample; V1 $(\mathrm{mL})$ represents the amount of measured sample; FW $(\mathrm{g})$ represents the fresh weight of sample.

\section{Results}

\subsection{Adaptation of stipagrosits pennata to drought}

The boundary region of desert, where Stipagrosits pennata grows, belongs to continental temperate zone and drought desert climate. The annual average precipitation is about $117.2 \mathrm{~mm}$, and the potential evaporation is up to $1942.1 \mathrm{~mm}$. The annual average temperature is $5-11^{\circ} \mathrm{C}$, the lowest temperature recorded is $-42.6{ }^{\circ} \mathrm{C}$ and the highest temperature is $62.2^{\circ} \mathrm{C}$. In the desert, the surface temperature can be as high as $60^{\circ} \mathrm{C}$. High temperature leads to the amount of water evaporation more than the amount of precipitation. It demands stipagrotsits pennata having a fully developed water-absorption and water-storage system, and meanwhile a structure minimizing water evaporation. Stipagrotsits pennata's root grows deep into earth for 4 to 5 meters to absorb water from deep underground. It has an average of more than 80 well-developed entwined lateral roots of 5 to 15 meters in length, radially extended into sand layers 6 to 35 centimeters below the ground, which can absorb water from the distant place without competing with other plants. Moreover, stipagrotsits pennata's root will develop new tiller buds at places with relatively sufficient water supply. As a result, stipagrotsits pennata clusters together at desert and has powerful vitality. These are the reasons that stipagrotsits pennata can grow without obvious suffering even when the water content is only $0.22 \%-4.33 \%$ in sand layers of $0-30$ 
cm depth.

Stipagrotsits pennata, perennial herbaceous, has the following features: smooth sheath, mostly shorter than internodes; dwarf membraneous ligule with extremely short cilia; vertically winded needle-shaped leaves up to $20 \mathrm{~cm}$ in length; thickly growing stalks with smooth branches, up to $50 \mathrm{~cm}$ in height. For adaptation to the windy climate during its growth period from May to June, its tenuous and flexible stems and leaves swing in wind and are not susceptible to break, meanwhile, its strongly curling leaves can prevent water from excessive evaporation (Mamat, Yiti, 1990, p. 51-56).

The lateral root of stipagrotsits pennata has an entwined structure, which holds a thick layer of sand and increases the friction between the sand and roots. The structure has a function of preventing sand flow and insulating the root from the overheated sand surface to prevent the root from heat damage as sand has relatively low thermal conductivity. From figure 1 (microstructure of root), we can see that, different from the root of other plants with which root hairs are found only at 2-3 cm over root tip, root hairs grow over the entire root surface to increase its hygroscopic capacity. In addition, the tight attachment between root hairs and sand can effectively stabilize the root into mobile dunes. From figure 2 and figure 3 (anatomic structure of root), we can see that root hairs are closely connected to epidermal cells, and there is a hollow airtight chamber between epidermal cells and parenchyma cells. The chamber is as a vacuole in plant, with many cabins separated by connection belt. Its cell wall is thicker than that of parenchyma cell at 3-4 times, and thicker than that of epidermal cell at 2-3 times, which provides better pressure resistance for water storage. Three or more drapes linked between epidermal cell and chamber cell wall facilitate the water absorption from sand to root hairs and the water transportation from root hairs into root chamber. As in a reservoir, the chamber generally stores water, and releases until the plant needs. In this way, stipagrotsits pennata adapts well to the intermittent rainfall in desert. The chamber, with 3 root hairs and 2-4 pellicular cells inside (figure 2), is so large that water therein can be easily transported to the well-developed tube in root, which in turn ensures the long distant transportation of water to the other parts of plant.

\subsection{Adaptation of stipagrosits pennata to cold climate}

It is the well-developed root that ensures perennial herbaceous stipagrotsits pennata to live in the desert with annual average temperature of $5-11^{\circ} \mathrm{C}$ and the extremely low temperature at $-42.6^{\circ} \mathrm{C}$. The sand layer tightly held on the root can insulate the root from outside cold hardiness and keep the winter bud warmed; on the other hand, there is no water in the root chamber in winter, such hollowed structure can protect the root from frostbite.

\subsection{Nutrient absorption process of stipagrosits pennata for adaptation to desert}

No matter what kinds of roots they are and which directions the roots extend into, the well-developed roots of stipagrosits pennata not only absorb water and nutrient from long distance, but also extend along a certain direction to a proper site to tiller for reproduction and further enhancing vitality. With drift of sand, stipagrosits pennata can absorb nutrients from new sand. The root of stipagrosits pennata can extend outward more than $15 \mathrm{~m}$ in sand because the viscosity of sand is much less than that of soil. All these make stipagrosits pennata well adapted to live in desert. Although the precipitation in desert is very little and the water content in top layer sand is only $0.22 \%-4.33 \%$, the absorbed nutrients therein is much more concentrated.

\subsection{Stoma changes of stipagrosits pennata for adaptation to desert}

Temperature affects stomata conductance drastically. Average stomata opening is very small around $24{ }^{\circ} \mathrm{C}$, increases with the rise of temperature, decreases however when temperature is over $35^{\circ} \mathrm{C}$, but maintains at about 2 times of that at $24{ }^{\circ} \mathrm{C}$ (figure 5 and figure 6). It indicates that the evaporation rate of stipagrosits pennata reaches the maximum at 35 ${ }^{\circ} \mathrm{C}$, and stays stable after that to prevent excessive evaporation resulted in withering.

\subsection{Simulate the adaptation to desert by PEG6000 simulated stress experiment}

Observe the differences among samples processed with 3 different concentrations of PEG. At the beginning, three different types of samples maintain the same. After 36 hours, membrane permeability increases in accordance with the concentration of PEG. This is because the samples don't need this much water. It increases the membrane permeability to absorb water only under the stress of drought. After 72 hours, all the samples still show healthy outlook, while cotton samples processed by $25 \%$ PEG died for lack of water after 48 hours.

Figure 7 and figure 8 show that the concentration of soluble protein in stipagrosits pennata is increased in accordance with the concentration of PEG. The content of soluble protein stressed with $20 \%$ and $30 \%$ PEG is $20 \%$ higher than that stressed with $10 \%$ PEG. It is $50 \%$ higher than that of the Control Group. It indicates that the content of soluble protein inside stipagrosits pennata is very low under stress-less circumstance, however gradually increases against the high osmotic potential caused by drought stress in order to keep absorbing water from its surroundings.

\section{Discussion}

There are two kinds of reproduction mechanisms for stipagrosits pennata: one is asexual propagation, namely, the 
tillered root grows up into a independent young plant, this mechanism is an effective way to reproduce in drought desert; the other one is sexual propagation, namely, stipagrosits pennata flowers and bears fruit from June to August, then its seeds germinate from March to April next year. Very small number of seeds has a chance to grow up due to rather limited amount of matured seeds, high temperature, drought in desert, and likely consumed by birds and insects, etc.

The root stipagrosits pennata presents itself as a long and slender entwined sand mass and with no entwined structure on the tip of root. It is difficult to investigate the structure, especially the microstructure of the entwined root directly from wild stipagrosits pennata. Cultivation of aseptic seedling can solve this issue. Cell membrane of root hair is similar to the membrane of thin wall cell. Water can easily pass through the thin wall of cell into epidermal cell of root hair. The entwined root can fix stipagrosits pennata onto sand tightly. Moisture sand itself is sticky. Entangled with the moisture sands, the roots will better fasten to the sand. In summer, the surface temperature can go up to $60{ }^{\circ} \mathrm{C}$. Aged roots are often exposed to the shallow layer of sand due to wind erasure. Entwined effectively protects the root with a layer thermal insulator. Entwined root has strong physical and chemical properties, and is able to remain its original form even under long-term contact with cellulose, pectase or $6 \mathrm{~mol} / \mathrm{L}$ hydrochloric acid. Polysaccharide secreted from the self-formed entwined root of stipagrosits pennata makes the entwined structure sticky (M Sridhara Murthy, 1975, p. 243-249; Ma, Wei, 2007, 55-56). The formation of entwined root shows important ecological function and significance. The root of rice stays in oxygen-short water in general, so the chamber in rice root is used for respiration. However, the chamber in stipagrosits pennata's root is used to store water against the drought in desert where water is in constant shortage expect when snow accumulated in winter melts and few plants can survive in such environment.

Besides the special structure of entwined root (Pathan M S, 2004, p. 525-569; Serraj R, 2002, p. 333-341), stipagrosits pennata exhibits different metabolic strategies for adaptation to drought stress (Tabaeizadeh Z, 1998, p. 193-247). Stipagrosits pennata is proved to be an excellent resource for drought resistance genes with excellent tolerance to drought, good resistance to high and low temperature fluctuation, etc. Through the investigation of this special plant, revelation of mechanism for adaptation to desert, and research on its genetic basis, and screening and cloning of drought resistance genes, we can acquire its potential gene resource for crop improvement. The research in this area has huge academic and economic value. Currently, there is very limited research on stipagrosits pennata in the world, especially on drought resistance genes and relative biomacromolecule.

\section{Acknowledgements}

The study is completed in the National Key Lab of Agricultural Biotechnology, College of Life Science, Shihezi University. I hereon thank Dr. Yuxing Zhang and Dr. Jianbo Zhu for their guidance.

\section{References}

Boyer J.S. (1982). Plant productivity and environment. Science, 218, 443-448.

Bray E. A, Bailey-Serres J \& Weretilnyk E. (2000). Responses to abiotic stresses in biochemistry and molecular biology of plants. In Gruissem W, Buchannan B \& Jones R (Eds.), American Society of Plant Physiologists, pp. 1158-1249.

Chaves M M \& Oliveira M M. (2004). Mechanisms underlying plant resilience to water deficits: prospects for water-saving agriculture. $J$ Exp Bot, 55, 2365-2384.

Chen, Xuesen, Deng, Xiuxin \& Zhang, Wencai. (1997). Effects of medium and culture environment on flavonoid production of ginkgo biloba callus. Journal of gardening, 4, 373-377.

Hao Zaibin, Cang Jing \& Xu Zhong. (2004). Plant physiology experiment. Harbin: Publisher of Harbin Institute of Technology.

M Sridhara Murthy \& R Ravindra. (1975). Allelopathic effects of a ristida adscensionis. Oecologia Berl, 18, 243-249.

Ma, Wei \& Li, Chunjian. (2007). Root sheath of plant and its ecological significance. World Agriculture, 4, 55-56.

Mamat, Yiti. (1990). Ecological and biological characteristics of stipagrosits pennata and evaluation on them. Arid Zone Research, 4, 51-56.

Mao, Weiguang, Weng, Mangling, Wu Zhen \& Li Shijun. (2006). The influence of different processes to the germination characteristics of leaf beet seeds. Jiangsu Agricultural Sciences, 3, 116-118.

Pathan M S, Subudhi P K, Courtois B \& Nguyen H T. (2004). Molecular dissection of abiotic stress tolerance in sorghum and rice. In Nguyen H T \& Blum A (Eds.), Physiology and biotechnology integration for plant breeding. Marcel Dekker Inc. p. 525-569.

Serraj R \& Sinclair T R. (2002). Osmolyte accumulation: can it really help increase crop yield under drought conditions? Plant Cell Environ, 25, 333-341.

Shinozaki K, Yamaguchi-Shinozaki K \& Seki M. (2003). Regulatory network of gene expression in the drought and cold stress responses. Curr Opin Plant Biol, 6, 410-417. 
Tabaeizadeh Z. (1998). Drought-induced responses in plant cells. Int rev cytol, 182, 93-247.

Vinocur B \& Altman A. (2005). Recent advances in engineering plant tolerance to abiotic stress: achievements and limitations. Curr Opin Biotechnol, 16, 123-132.

Wang W, Vinocur B \& Altman A. (2003). Plant responses to drought, salinity and extreme temperatures: towards genetic engineering for stress tolerance. Planta, 218, 1-14.

Yamaguchi-Shinozaki K \& Shinozaki K. (2005). Organization of cis-acting regulatory elements in osmotic and cold stress responsive promoters. Trends Plant Sci, 10, 88-94.

Zhou, Jiyuan \& Dai, Jungui. (1997). Effects of plant growth regulators on callus formation and organogenesis of astragalus chinensis 1. Journal of Central China Normal University (Natural Sciences), 1, 77-82.

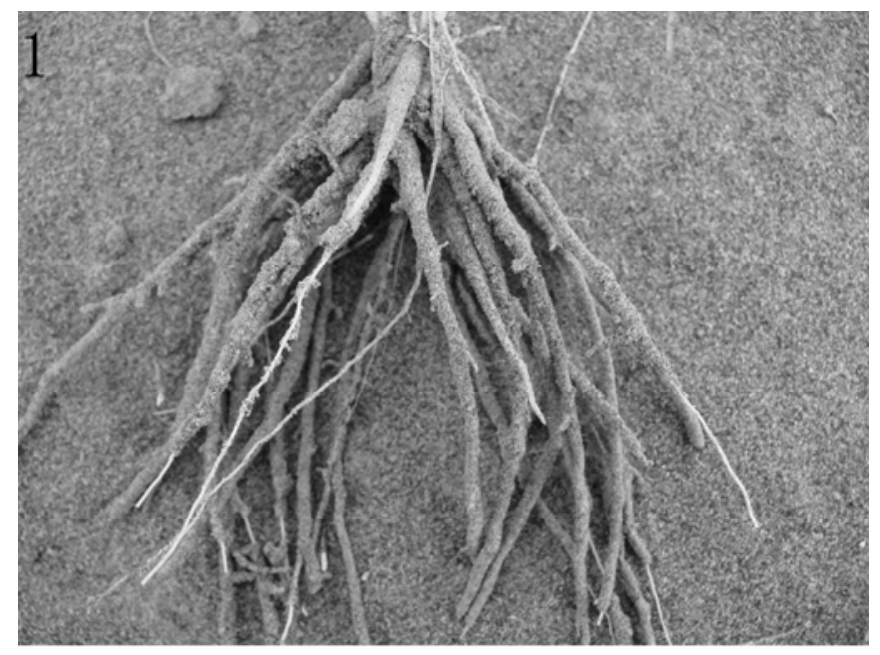

Figure 1. Wild stipagrostis pennata and roots set

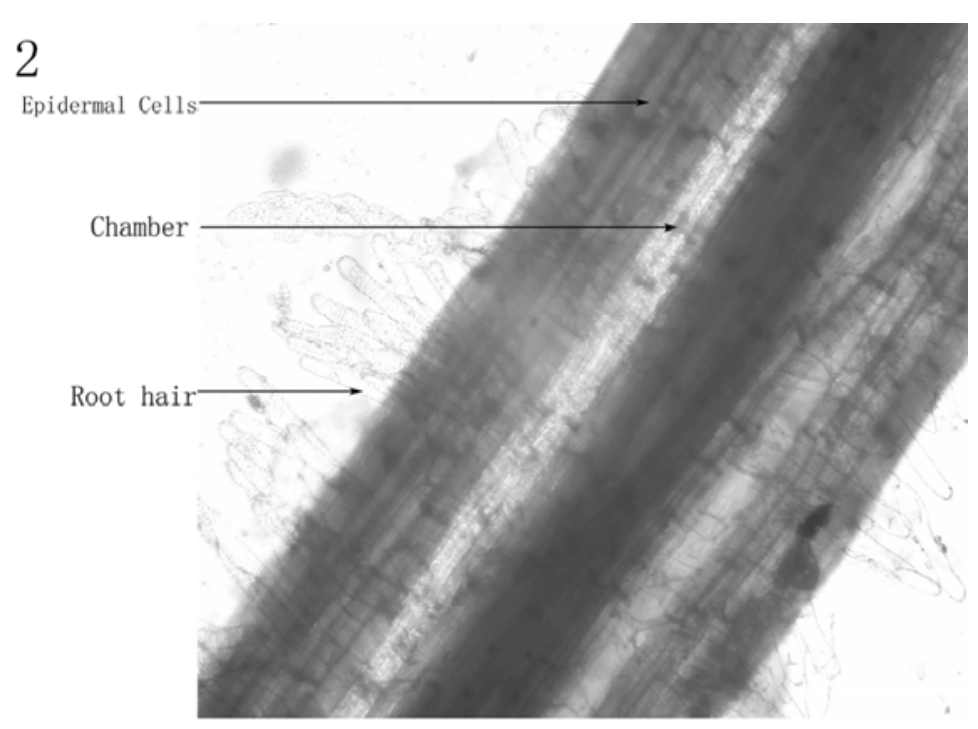

Figure 2. Root hair in medium 


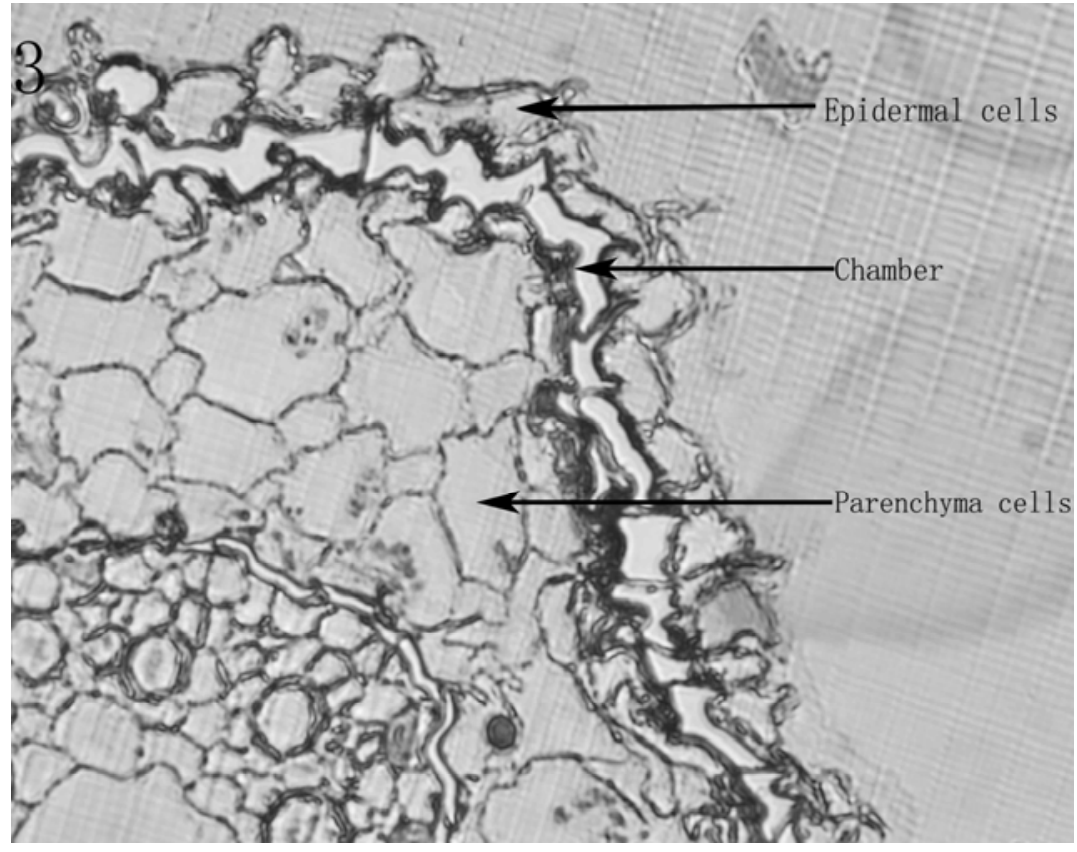

Figure 3. Dyeing of safranine and fast green

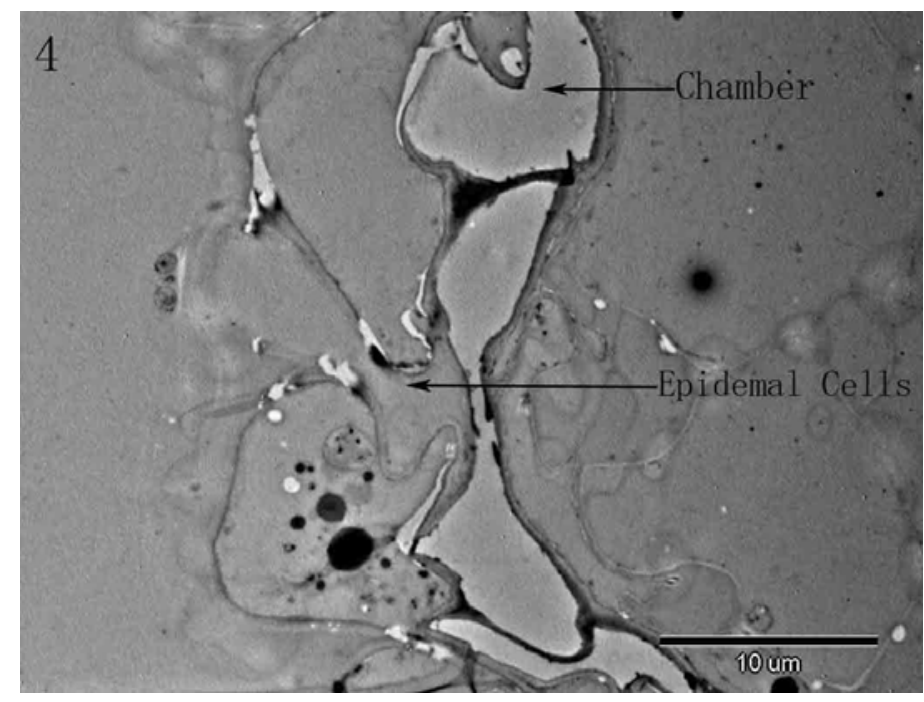

Figure 4. Roots set structure by electron microscope

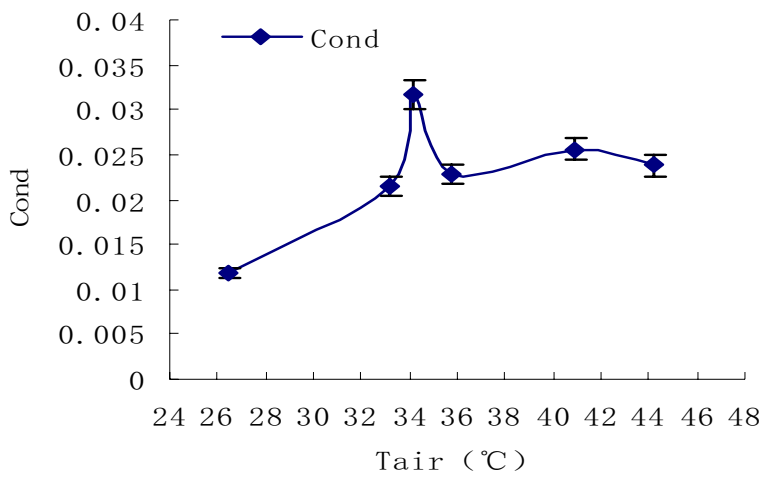

Figure 5. Effects of air temperature on conductivity 


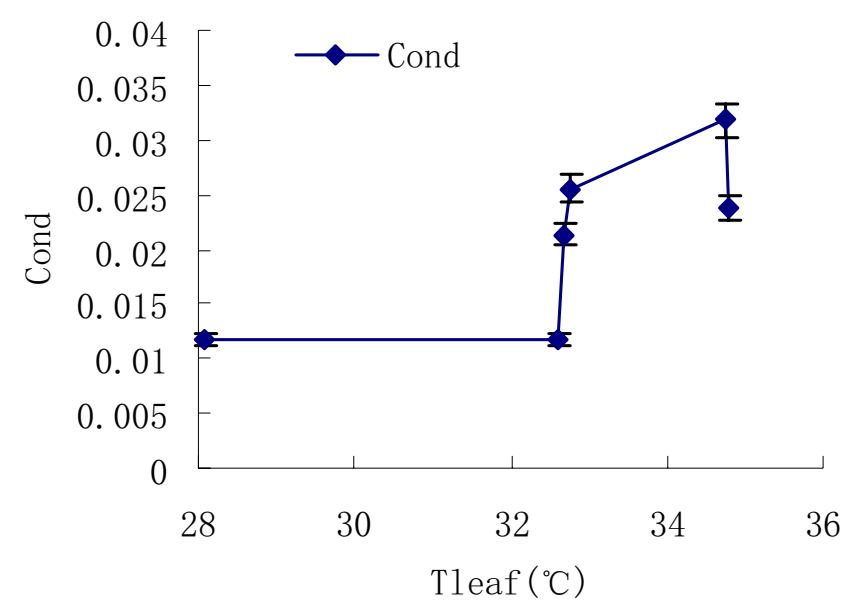

Figure 6. Effects of leaf temperature on conductivity

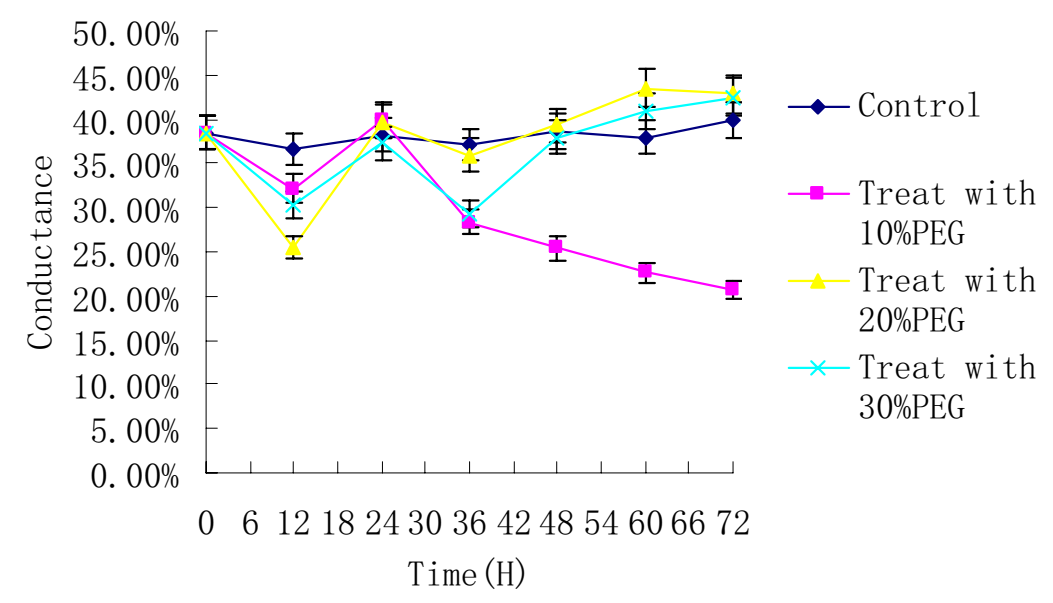

Figure 7. Effects of PEG6000 on membrane permeability

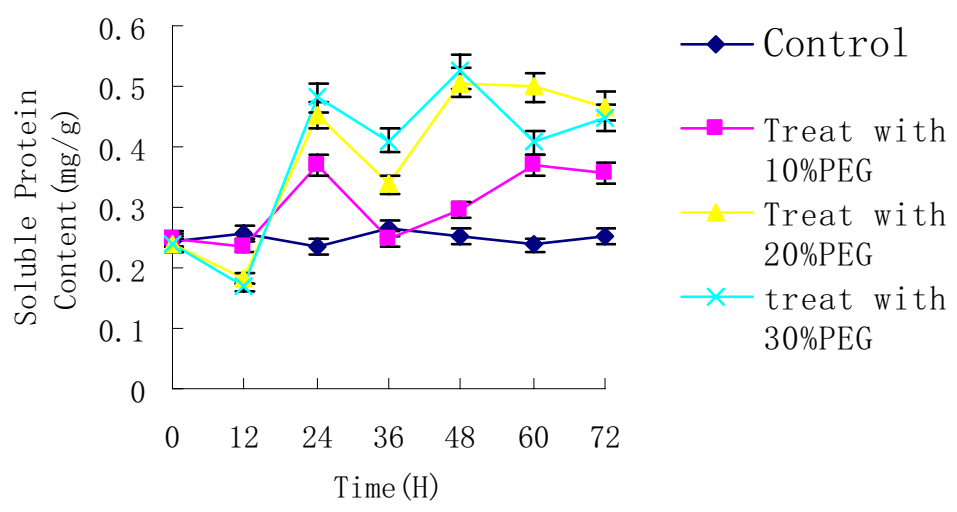

Figure 8. Effects of PEG6000 on soluble protein content 